\title{
Tseng Kwong Chi: Performing for the Camera
}

Grey Art Gallery, New York University, New York, NY, USA, 21 April-11 July 2015

New York, New York (1979), the first photograph by Tseng Kwong Chi encountered in the exhibition Performing for the Camera, captures the artist midjump, one hand raised in an ebullient fist, the other holding the button that operates the shutter on the camera (fig. 1). The Brooklyn Bridge and Brooklyn Heights are perfectly framed behind him. The visual grammar of the triumphant, frozen leap (a trope now being parodied in GEICO commercials) is familiar to anyone who has ever watched a John Hughes film, except that Tseng is in a Mao suit and wearing dark glasses. The solemnity of the outfit and the carefully posed landscape work in perfect friction with Tseng's body and demeanour. This juxtaposition of gravity and glee is a perfect synecdoche for the period in which Tseng produced the various projects featured in this exhibition, a little more than a decade after Stonewall, when the 1980 s body-checked queer people with the double blows of President Ronald Reagan's conservative revolution and the crisis of HIV/AIDS. Tseng himself died of AIDS in 1990, and this exhibition establishes him as a major artist who has been overlooked and overshadowed for almost a quarter of a century.

New York, New York is part of the East Meets West series of images that feature Tseng playing the "ambiguous ambassador" as he poses stoically (with some exceptions) in front of various landmarks and natural formations. The series blends into his series of self-portraits, sometimes taken at clubs, where he photographed himself with party-goers or infiltrated cultural events. A large number of images document his crashing and covering the Metropolitan Museum of Art's star-studded reception for their 1980 exhibition The Manchu Dragon: Costumes of the Ching Dynasty. Appearing with celebrities including William F. Buckley, Jr., Paloma Picasso, Andy Warhol, and Nancy Kissinger, Tseng is a visible reminder that he is the only person at the ball who shares any heritage with the work on display.

Tseng's work addresses the politics of the decade with full force and gleeful parody. Perhaps the most surprising images in the exhibitions are a suite of portraits comprising the Moral Majority series (1981), depicting conservative politicians posing in front of a dreadfully wrinkled American flag that Tseng had convinced them would appear to wave in the final image. The portraits were commissioned by the Soho Weekly News and ran as an article about the face of the Reagan revolution. This sort of gathering of important people remains a mainstay of Richard Avedon and Annie Liebovitz retrospectives, but in Tseng's photographs, the depicted individuals are candid and unguarded. 


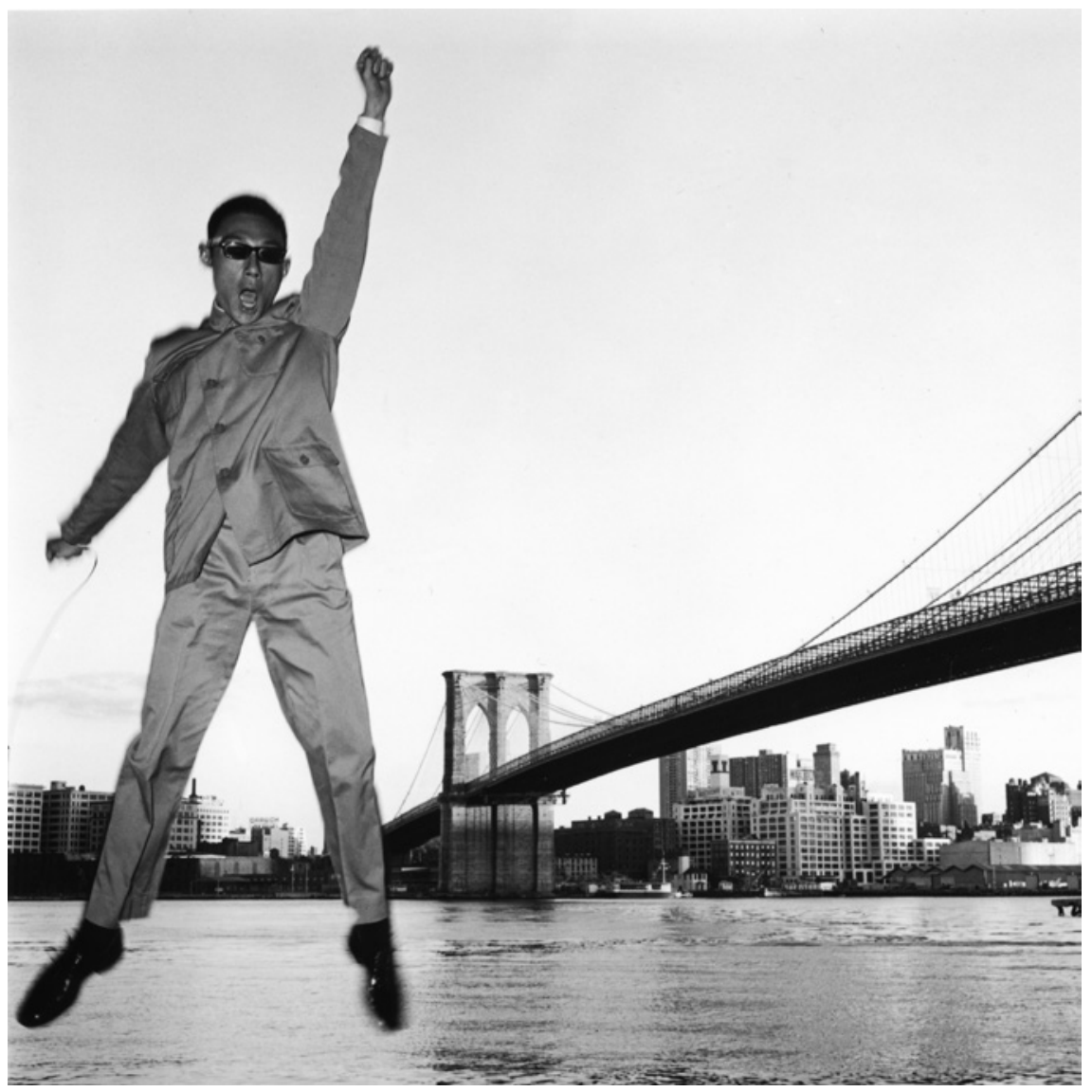

FIgURE 1 Tseng Kwong Chi, New York, New York (Brooklyn Bridge), 1979, from the series East Meets West series. Gelatin silver print, $36 \times 36$ inches $(91.4 \times 91.4$ centimetres $)$. COURTESY MUNA TSENG DANCE PROJECTS, INC., NEW YORK.

William F. Buckley Jr. looks positively charming, and Jerry Falwell, open and warm. John "Terry" Dolan touches his face in a way that calls to mind Renato checking his makeup in La Cage Aux Folles. While the images are presented as skewering the subjects, I found them surprisingly charismatic. For this series, Tseng foregoes his foreboding "ambiguous ambassador" guise in favour of "young Republican" drag. In a seersucker suit he looks every bit the smug striver, though his impish smile suggests how he delights in the subterfuge.

In another set of images for the Soho Weekly News, Tseng dressed his downtown friends in yuppie drag and photographed them for a layout called It's a Reagan World! with text by Ann Magnuson. The parody is dead on, showing the 
crowd looking outdoorsy and prosperous in front of large homes on big lots. For those of us who came of age after the 1980s, or remember the decade from our childhoods, gay culture from that period often seems humourless. Larry Kramer's shrill notes in The Normal Heart and the kitsch of Longtime Companion can make the decade feel like one that was lived in as much tortured gravity as the work that survives it. Tseng's work is a reminder that not all opposition is grim; not all fights are joyless.

In the Mao suit images, Tseng is both hypervisible and anonymous. His costume and demeanour evoke Western fascinations with (and fears of) communal identity and self-effacing efficiency. Tseng's body is the focus, and yet the whole point of his personal appearance is to suggest that he is one of many; yes, he is nearer to the top of the food chain, and yet he continuously appears to my eyes as a functionary, rather than a dignitary. He positions himself next to people who preen with individualism and landscapes that are loved for their particularity, precisely because his conformist image throws them into focus. Like a picture of the Earth from outer space, Tseng offers the West its other. In the American imaginary, non-white bodies carry the burden of racialization (so that whiteness can go unmarked). Tseng's foregrounding of his body does not undo American whiteness, but it certainly marks it as visible.

Behind the camera, Tseng is invisible by necessity, and no more so than when documenting Keith Haring's work. Haring is the moon to Tseng's sun in this exhibition, the former constantly threatening to eclipse the latter as he did in life. In its brief obituary for Tseng, the New York Times named Haring five times - the same number of times that Tseng himself was named. The necessity of this exhibition is that it argues for Tseng as an artist in his own right, and once the viewer has learned to see (or to realize that they have been seeing) Haring's work through Tseng's eyes, his shaping hand becomes visible in the documentation. The two were extremely close. The exhibition wraps with a 1983 series of well-known images of Bill T. Jones, his body painted by Haring with undulating white stripes, his movements photographed by Tseng. It is undoubtedly the effect of white supremacy that when I first saw these images as an adolescent, they were presented to me (or at least, I saw them) as the work solely of Haring, when in fact they were a collaboration by a multiracial group of inspired artists.

Another name for the exhibition might have been Tseng and His Circle; like Mary Shelley or Frank O'Hara, Tseng was part of a vibrant group of artists who dramatically changed the direction of art. Warhol looms as the grandfather, but Jean-Michel Basquiat, Keith Haring, Bill T. Jones, Madonna, Joey Arias, and others make frequent appearances throughout. The Grey Art Gallery is an 
intimate space, and the feeling of friendship and connection pulled this viewer in. Tseng Kwong Chi's career was cut short, but what he accomplished in his time was prodigious.

\section{Jason Schneiderman}

Borough of Manhattan Community College-CUNY, New York, NY, USA jschneiderman@gmail.com

\section{Jason Schneiderman}

is the author of Striking Surface, winner of the Richard Snyder Prize from Ashland Poetry Press (2010), and Sublimation Point, a Stahlecker Series Selection from Four Way Books (2004). Schneiderman was the recipient of the Emily Dickinson Award from the Poetry Society of America in 2004, and a finalist for the Eric Hoffer Award in 2011. He is Poetry Editor of the Bellevue Literary Review, and Associate Editor at Painted Bride Quarterly. 